\title{
La visión de la "raza". Apuntes para un estudio de la fotografía de tipos raciales en Argentina
}

\author{
Sergio Caggiano* \\ ${ }^{*}$ CONICET - Instituto de Desarrollo Económico y Social (IDES) \\ E-mail: sergio.caggiano@gmail.com
}

RMA

Antropología Social

\begin{abstract}
Resumen
El artículo presenta algunas notas, reflexiones y, sobre todo, preguntas acerca de la fotografía de tipos raciales en Argentina, más precisamente en la antropología argentina de finales de siglo XIX y principios deI XX. Las fotografias de "tipo" han tenido un papel clave en la producción del propio concepto moderno de "raza". Luego de sintetizar los aportes de algunos autores para comprender esto, el artículo repara en algunas tempranas fotos de la antropología local. Ellas conducen a formular dos clases de preguntas. Unas a propósito del papel que podrían haber jugado las fotografías de "tipo" locales en esa configuración del concepto de "raza" que se difundiría por el mundo. Otras a propósito de la dinámica social que puede leerse congelada en dichas imágenes. Una preocupación general que sostiene el texto es expresada (o mejor, mostrada) desde el comienzo: ¿en qué medida este modo de ver puede estar presente o reactivarse en dispositivos visuales contemporáneos?
\end{abstract}

Palabras clave: Fotografía; Tipos raciales; Argentina.

The vision of "race". Notes for a study of racial types photography in Argentina

\begin{abstract}
This article shows some notes, considerations and, mainly, questions about photographies of racial types in Argentina, more precisely in the argentine anthropology of late s. XIX and early XX. The photographies of "type" have played a key role in the production of the modern concept of "race" itself. After synthesizing the contributions of some authors to understand this, the article pays attention to some early photos of the local anthropology. They lead to make two kinds of questions. Ones of them about the role the local photographies of racial types could have played in the configuration of the concept of "race" that would spread through the world. Others about the social relations which can be read -frozen in such images. A general concern that holds the text is expressed (or better, shown) from the begining: to what extent this way of seeing may be present or reactualized in contemporary visual devices?
\end{abstract}

Keywords: Photograph; Racial types; Argentina.

Las páginas que siguen reúnen algunas notas sobre la fotografía de "tipo racial" en la antropología argentina de finales del siglo XIX y principios del XX. Tienen la forma de apuntes para una investigación futura, y por eso formulan más interrogantes que afirmaciones conclusivas. Si bien trata sobre fotografías antiguas, este trabajo se originó mientras realizaba un estudio sobre repertorios visuales contemporáneos, correspondientes a la primera década del presente siglo. El detonante para que se abriera esta exploración paralela de materiales y su análisis fue el encuentro con fotografías que, producidas y publicadas en años recientes, reiteraban trazos característicos de aquellas fotografías de "tipo" del siglo XIX. Las imágenes actuales reproducían su encuadre y su composición, y apelaban a los tradicionales etiquetamientos generalizantes en sus leyendas.

La foto del "Nativo guaraní actual" (f. 1), por ejemplo, pertenece a un manual escolar producido en Buenos Aires en 2006, dirigido a niños de nueve años y que fue distribuido y utilizado en escuelas de distintos lugares de Argentina. Más allá de tratarse de una imagen en color, los restantes rasgos formales recuerdan a los de aquellas fotografías: se enfoca el torso desnudo del "Nativo guaraní" en primer plano y de frente, así como su rostro que mira a la cámara; se aprecian sus rasgos físicos y pocos elementos más. El pie de foto completa la caracterización. "[P]or medio de la yuxtaposición de una forma y una leyenda representacionales específicos [...] los «tipos» son establecidos o [...] un individuo consigue tornarse una generalidad. Leyendas generalizadoras como «Un nativo típico», «Una beldad nativa» [...] funcionan de esta forma" (Edwards 1992: 11).

Este fue solamente uno de los momentos en que el corpus heterogéneo de imágenes que trabajaba entonces me 


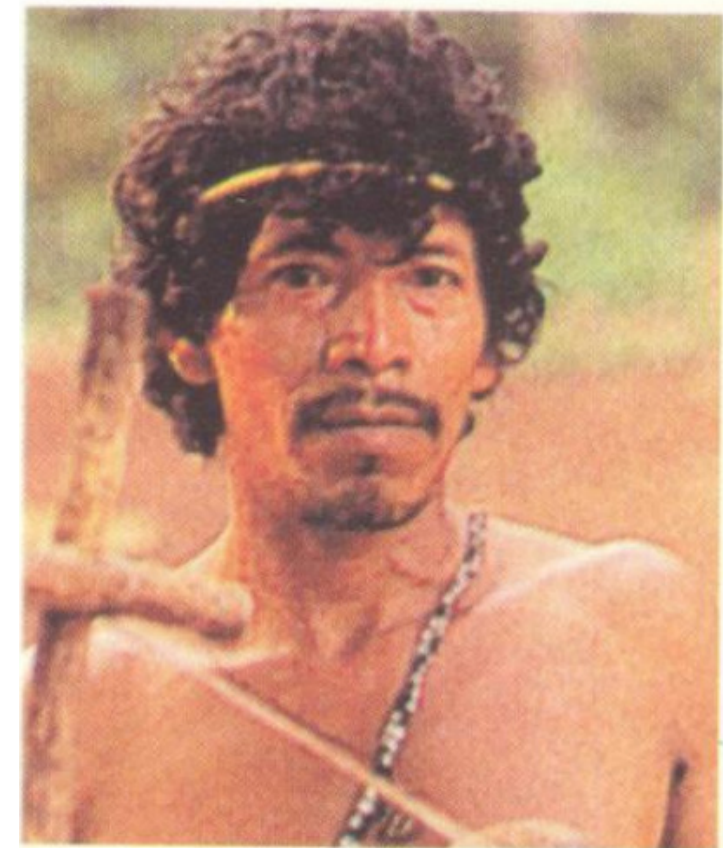

\section{Nativo guaraní actual.}

Figura 1. "Nativo guaraní actual". Manual de Ciencias Sociales, Tinta Fresca, 2006.

Figure 1."Guaraní native". Manual de Ciencias Sociales, Tinta Fresca, 2006.

trajo reminiscencias de las fotografías de "tipo racial". La imagen y el rótulo tipificantes reaparecían como una fantasmagoría en los manuales escolares, en sitios web de organizaciones indígenas o en la prensa gráfica de gran tirada (Caggiano 2012). Por ello, el rastreo histórico de imágenes en archivos y bibliotecas que inicié a partir de esos encuentros fue una búsqueda orientada a comprender elementos residuales (Williams 2000), es decir, fragmentos del pasado que operan activamente en la actualidad.

No obstante, las observaciones que presento aquí refieren a imágenes antiguas y a sus específicos contextos históricos de producción. Su elaboración, en la segunda mitad del siglo XIX, constituye un hito en la gestación de un modo de mirar que es, al mismo tiempo, un modo de percibir/interpretar al "otro". Las reflexiones y los interrogantes derivados de estas observaciones indagarán, por un lado, sobre la relevancia que esta producción local de imágenes puede haber tenido en la configuración de una mirada racial a gran escala y, por otro, sobre la complejidad del entramado social que puede entreverse en estas fotos y que forma parte de sus condiciones de producción.

\section{La construcción de una mirada racial}

Las fotografías de tipo han tenido un papel clave en la configuración de una comprensión racial (en su sentido moderno y "científico") de las sociedades y grupos humanos, haciendo mucho más que brindar la posibilidad de una representación icónica de algunos de los presupuestos racialistas. Estudios antropológicos e históricos de la fotografía (Poole 2000; Smith 1999 y 2004) han mostrado cómo la tecnología visual del tipo jugó un papel fundamental en la producción del concepto mismo de "raza".

En el contexto de transformación de las políticas coloniales, de modernización de los Estados nacionales periféricos y de transformación de las urbes metropolitanas y de sus dispositivos de regulación social, la consolidación de la antropología física en Europa y de otras disciplinas asociadas iba de la mano de la búsqueda de una clasificación exhaustiva de las "razas humanas". El recurso a métodos y técnicas como la craneometría o la medición del índice encefálico apuntaba a la comparación de grupos humanos para dividir la especie en "tipos", los cuales a su vez podían ser divididos en ramas, subramas y familias (Stocking 1968) ${ }^{1}$

La fotografía de tipo, para la que algunos han encontrado antecedentes en los dibujos y textos científicos de los viajes de exploración de Humboldt o de D'Orbigny de la primera mitad del siglo XIX, y que se asocia con las representaciones de oficios, las cartes de visite y las tomas policiales, encontró en la fotografía antropológica de fines del siglo XIX y comienzos del XX la materialidad y la objetivación de rasgos que las teorías racialistas modernas precisaban para su consolidación. "En el campo de la ambigüedad y fluidez que la «raza» constituye, la fotografía y las tecnologías visuales del «tipo» que la precedieron jugaron un rol crucial en la producción del propio concepto de la «raza»" (Poole 2000: 261). El encuadre que aislaba a la persona fotografiada del entorno, tomándola de frente, en general en un plano medio corto o en un primer plano, otorgaba dimensión física a la noción de "tipo" y ofrecía la materialidad que la mirada fisiognómica procuraba.

Cada uno a su manera, el francés Alphonse Bertillon y el británico Francis Galton han hecho aportes fundamentales a la constitución de estas fotografías de tipo. En un influyente artículo, Allan Sekula mostró algunas similitudes $y$, principalmente, las diferencias entre los sistemas de descripción del "cuerpo criminal" desarrollado alrededor de 1880 por cada uno de estos dos hombres. Los propósitos prácticos e individualizantes de Bertillon, antropólogo oficial de la policía parisina, lo llevaron a elaborar el sistema llamado "retrato hablado" (portrait parlé) que disponía realizar, para cada persona

\footnotetext{
1 Para una reconstrucción histórica de los conceptos de "raza" y "tipos raciales" puede consultarse, además de Stocking Jr. (1968), Arendt (1973), Banton (1977) y Malik (1996). Otros aportes críticos al respecto, en Guillaumin (2002) y Balibar (2003). Para la relación entre “tipo racial" y fotografía, Dias (1994).
} 
a ser registrada, un retrato de frente y de perfil y una ficha de archivo con nueve medidas de características fisiognómicas. Lograría sortear la maestría en el engaño de los criminales uniendo la "antropometría, la precisión óptica de la cámara, un refinado vocabulario fisiognómico y estadísticas" (Sekula 1992: 358)². Por su parte Galton, apuntando a visualizar la evidencia genérica de las leyes de la herencia, elaboró el sistema de las "imágenes compuestas" (composite images), que resultaban de la agregación de diversos retratos individuales que, a medida que se amalgamaban uno sobre otro en un único retrato (de una familia, de un grupo, de una "raza"), perdían en precisión pero al mismo tiempo, se pretendía, ganaban en representatividad media. Galton consideraba su más exitosa composición la que representaba al "tipo judío". Sekula sostiene que "el sistema nominalista de identificación de Bertillon y el sistema esencialista de tipología de Galton constituyen [...] los dos polos de los intentos positivistas de regular la desviación social por medio de la fotografía" (Sekula 1992: 373).

Shawn Michelle Smith continuó la revisión de Sekula, aunque con algunas enmiendas a su perspectiva. La autora estudia la construcción de la esfera privada y la interioridad a finales del siglo XIX en Estados Unidos como discurso (verbal y visual) de la emergente clase media, que encontraba allí una "esencial virtud", rasgo de clase que la oponía tanto a la aristocracia como a las clases trabajadoras. En este marco, Smith subraya que los estudios de Bertillon y las prácticas que él y algunos seguidores derivaron de ellos coexistieron con estudios criminológicos que enfocaban el cuerpo no como marcador de identidad individual sino como indicio de un tipo biológico más general. Así, por ejemplo, para Lombroso y su escuela, que recurren a la antropología física de Paul Broca, "el cuerpo sirve como índice de una interiorizada esencia criminal" (Smith 1999: 73). Para ellos el carácter innato podía rastrearse en el tipo físico. En su búsqueda del tipo, esta criminología coincidiría con el racialismo biológico desarrollado desde mediados del siglo XIX. Por esta vía Smith llega a la eugenesia y a su padre (vale la metáfora), Francis Galton, quien "definía y estudiaba ambos tipos, el criminal y el racial, como categorías biológicas" (Smith 1999: 86). Es en este sentido que tanto "las composiciones de Galton como las fotos (mug shots) de Bertillon refuerzan los discursos de clase media acerca de una interioridad sagrada, exclusiva, conteniendo y proporcionando un contraejemplo "amenazante»" (Smith 1999: 92). El cuerpo es codificado como un mapa de esencias interiores. En su superficie y en la superficie de la fotografía, que capta la del cuerpo, se podrá leer lo propio y lo extraño.

Poco tiempo antes, en Visión, Raza y Modernidad.

\footnotetext{
2 Vale apuntar que, con la apertura de la Oficina de Identificación Antropométrica en Buenos Aires en 1888, Argentina se convirtió en el cuarto país en el mundo en adoptar el sistema de fotografías y mediciones de Bertillon (Penhos 2009: 30).
}

Una economía visual del mundo andino de imágenes, Deborah Poole había señalado otra crítica al planteo de Sekula. Trabajando con cartes de visite de habitantes del Perú y, en menor cantidad, de Bolivia ("cholas", "mujeres limeñas", "bandoleros indígenas" y una extensa lista de oficios), la autora se sorprende porque las genealogías que vinculan dichas cartes con la fotografía policial de Bertillon han sido suprimidas por los críticos de la fotografía "quienes persisten en abordar la fotografía como un discurso y tecnología exclusivamente europeos" (Poole 2000: 173). Advierte, entonces, que la carte de visite de 1860 y 1870 sentó las bases para el principio de equivalencia o comparabilidad necesario para el desarrollo de los archivos policiales de Bertillon, así como para las mediciones de poblaciones racialmente diferenciadas que antropólogos físicos realizaron en los andes siguiendo su sistema. De hecho, "[l]a importancia que la carte colonial o de tipo tuvo en la consolidación del sistema archivístico de intercambios y equivalencias que sería fundamental para el sistema de Bertillon" se ve también en el hecho de que éste utilizara "cartes de visite como ilustraciones para su primera publicación profesional, Les Races sauvages", de 1882 (Poole 2000: 172).

Esta breve revisión es suficiente para poner de relieve tres elementos. En primer lugar, y en términos generales, la mencionada relevancia de las fotos de tipo para el establecimiento de una mirada racializadora. En segundo lugar, las diferencias y discrepancias acerca del proceso de génesis de tales fotografías de tipo, que revelan que se trata de una discusión abierta. Por último, las relaciones de fuerza que posibilitaban estas tomas, es decir, el desequilibrio de poderes entre los científicos fotógrafos o fotógrafos científicos y sus otros en tanto "objetos".

\section{Las fotografías de tipo en la antropología argentina}

Ese sobrio dispositivo visual que fue la fotografía de tipo recibió gran atención en los comienzos de la antropología local. Algunos antropólogos argentinos, o extranjeros que trabajaron en el país, produjeron en gran número el doble retrato bertillonesco de frente y perfil, con fondo neutral, vaciado de referencias contextuales, que permitía concentrar la mirada en las proporciones y los rasgos fisonómicos del retratado o la retratada, a quien a veces se descubría de ropas el cuerpo, al menos en su mitad superior.

En el Departamento de Documentos Fotográficos del Archivo General de la Nación (AGN), en los sobres y cajas a los que se llega desde el sector del fichero correspondiente al tema "Aborígenes", se conservan fotografías como las de las figuras 2 y 3 . La mujer de la primera de ellas está identificada en el reverso de la foto como la "Hija de Rufino Vera, india araucana" y el hombre de la 3 como "Chagayo. Indio puelche pampa". En el Museo Etnográfico Juan B. Ambrosetti también 


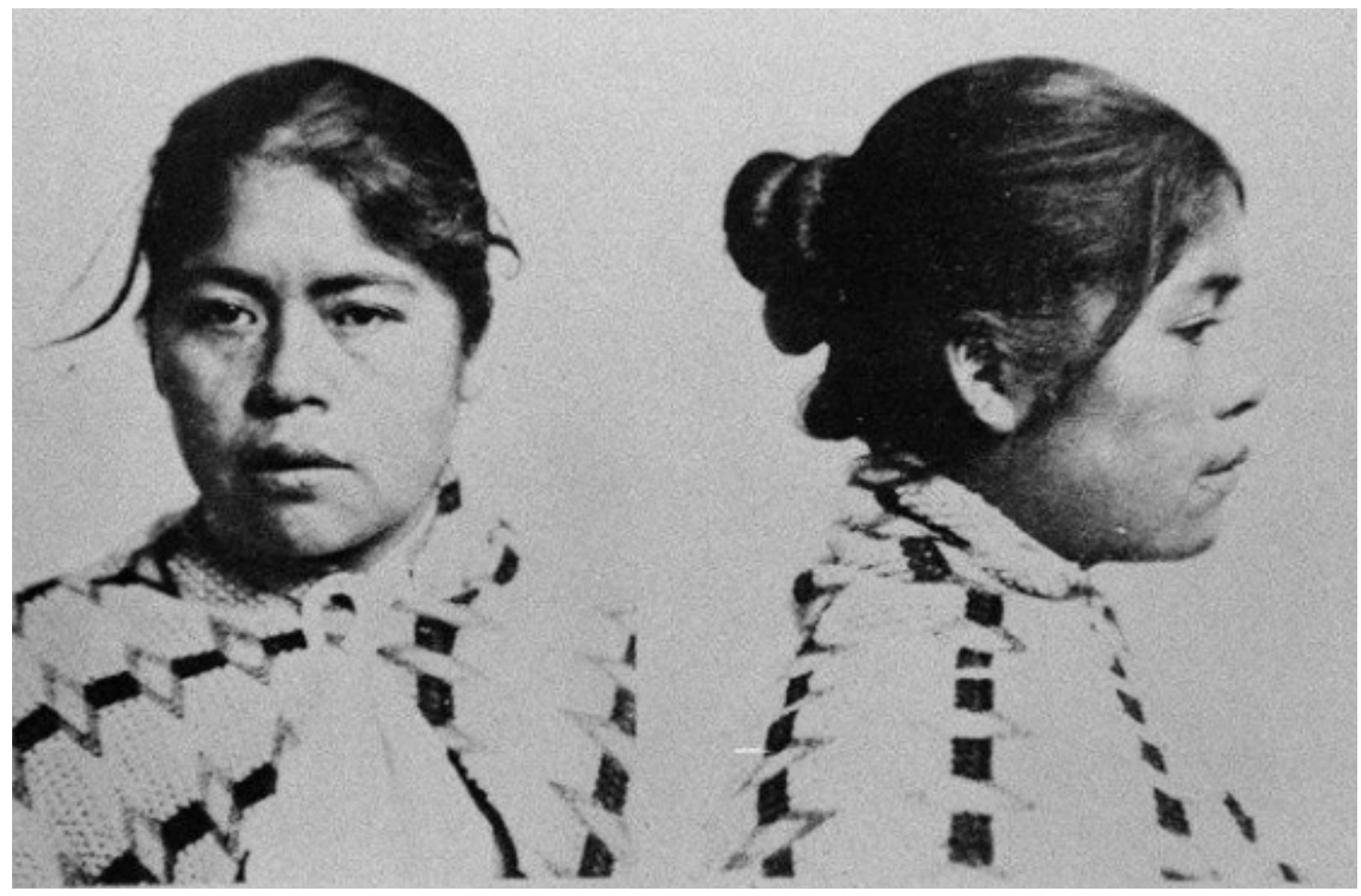

Figura 2. "Hija de Rufino Vera, india araucana", Archivo General de la Nación.

Figure 2. Rufino vera's daughter. Araucanian indian, Archivo General de la Nación.

se conservan varios ejemplares de estas tomas, así como fotografías del momento mismo de su realización mediante el "aparato de Bertillon"3. En el Museo de La Plata existe una importante cantidad de estas fotografías, algunas de ellas publicadas en revistas de fines del siglo XIX y principios del XX y otras inéditas, que recientemente han llamado la atención de algunos/as investigadores/as ${ }^{4}$. La visualización de tipos raciales humanos parece haber sido una preocupación en este "momento fundacional" de la antropología argentina (Fígoli 2004: 72), cuando la antropología física crecía en consonancia con las ciencias naturales, en diálogo con la medicina, la psiquiatría o la criminología y en relación con el desarrollo de los museos

3 El "aparato" o la "silla de Bertillon" consistía básicamente en una silla que permitía mantener recto y rígido el cuerpo de la persona a retratar. Además de la pose, el sistema prescribía la distancia focal, el ángulo, el plano y las condiciones de iluminación. Dando suma precisión a estos aspectos, Bertillon "proponía elevar la fotografía a la categoría de la ciencia exacta y la estadística" (Poole 2000: 168). Acaso para dar cuenta de la exactitud y el rigor con que seguían el método, los científicos que recurrieron a este sistema acostumbraron dejar constancia de ello justamente mediante fotografías del instante de su aplicación.

4 A partir de la experiencia de rescate, identificación y clasificación de una serie de fotografías halladas en el Archivo Fotográfico del Museo, Martínez y Tamagno (2006) analizan un conjunto de ellas, tomadas por Carlos Bruch y en parte publicadas por Roberto Lehmann-Nitsche en un artículo de 1907 en los Anales del Museo de La Plata (LehmannNitsche 1907). En otras publicaciones del Museo de la misma época es posible encontrar fotografías similares. Respecto de las colecciones fotográficas del Acervo Histórico de la Facultad de Ciencias Naturales y Museo de la Universidad Nacional de La Plata y del reciente proyecto de rescate, conservación, microfilmación y digitalización de una parte de este acervo, ver Garrido, Kelly, Martínez y Podgorny (2007).
(Podgorny y Lopes 2008; Farro 2009).

Dicha visualización se realizó indudablemente siguiendo el método de Bertillon, y quizá también el de Galton, ya que si bien en mi exploración de ilustraciones de los antropólogos de la época no hallé "imágenes compuestas" realizadas según la propuesta de este último, encontré en el Museo de La Plata un pequeño fascículo técnico editado en París en 1887 y que probablemente haya pertenecido a los Talleres de Publicaciones del Museo, llamado La photographie appliquée a La Production du Type d'une familla, d'une tribu ou d'une race, en el cual el autor ensalza, explica y ejemplifica ese "maravilloso trabajo de análisis y de síntesis" que es la fotografía compuesta de Galton (Batut 1887).

Es precisamente hacia este Museo donde conducen las referencias de las fotos de tipo del Archivo General de La Nación. Las figuras 2 y 3 y otras muchas del mismo estilo llevan en su dorso la inscripción "Foto publicada en el libro Iconografía Aborigen, de M. A. Vignati, Tomo I".

Milcíades Alejo Vignati reemplazó a Robert LehmannNitsche, tras su jubilación, al frente de la cátedra y el Departamento de Antropología del Museo de La Plata. Fue clave en el desarrollo de la antropología física en el Museo de La Plata y abordó también temas de arqueología, prehistoria, etnología, etnohistoria y lingüística (Soprano s/f). Vignati elaboró su "Iconografía Aborígen" en tres partes, presentadas en respectivos ejemplares de la Revista del Museo de La Plata entre 


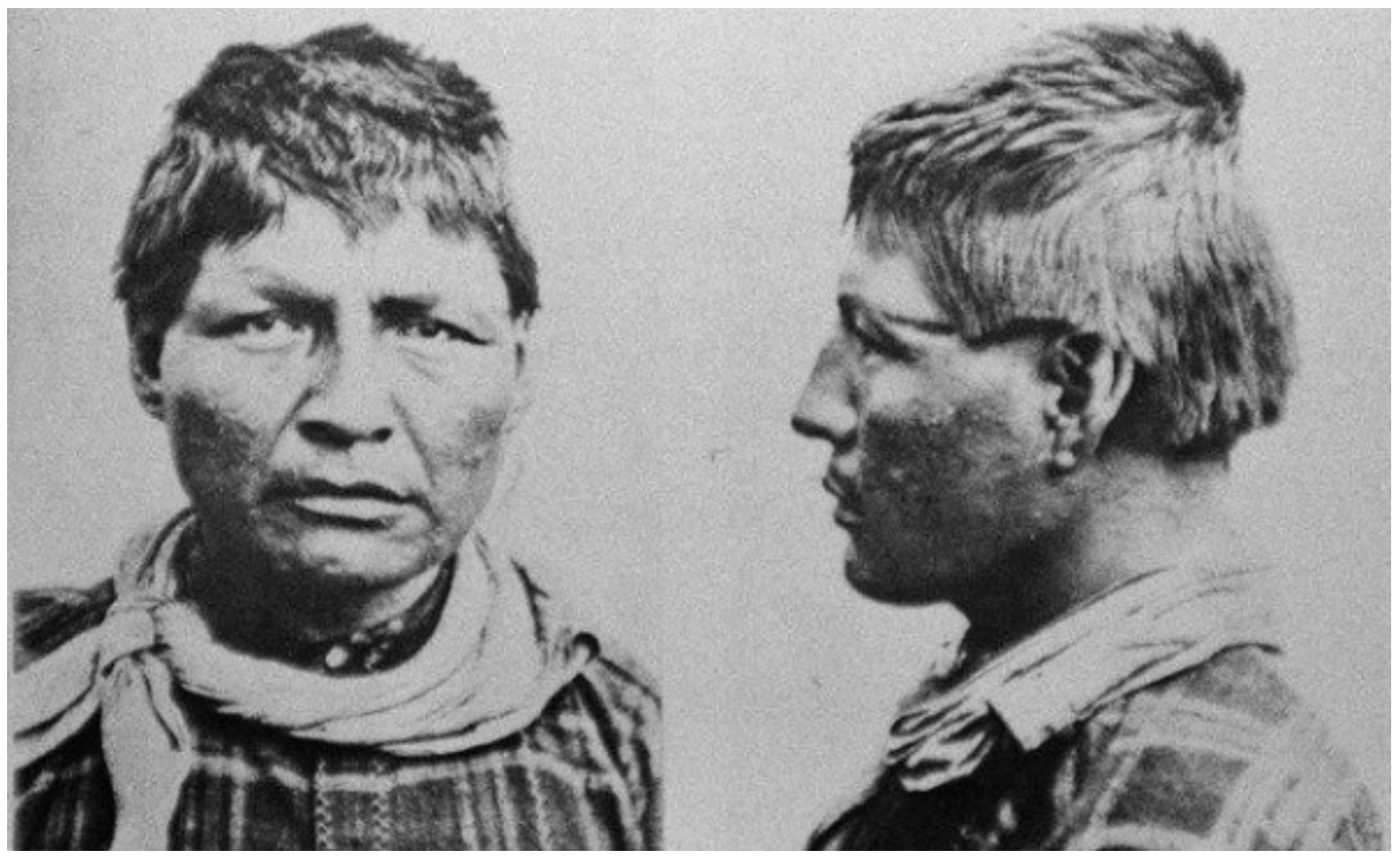

Figura 3. "Chagayo. Indio puelche pampa", Archivo General de la Nación.

Figure 3.Chagayo. Puelche pampa indian, Archivo General de la Nación.

1942 y 1946 . En el resumen que acompaña la primera de ellas el autor expone sus propósitos:

“No obstante estar en trance de desaparición, son pocas las representaciones gráficas existentes de los aborígenes de Patagonia. Por ello es que se ha querido salvar una serie de negativos de los últimos caciques con mando que, en carácter de prisioneros, fueron traídos a Buenos Aires en 1884. Se ha reunido para cada uno de ellos los antecedentes de su vida y actuación procurando destacar su psicología" (Vignati 1942: 46).

En el cuerpo del texto es aun más preciso:

"En ningún momento he tenido la intención de realizar exclusivamente un muestrario de tipos indígenas; no obstante el valor intrínseco que tendría en calidad de álbum dedicado al conocimiento racial de nuestras tribus aborígenes, he querido, por el contrario, restituir a este conjunto un poco de vida, derivada de la honda simpatía que -malgrado sus taras racialesprovoca su conocimiento a través de las crónicas de quienes los trataron" (Vignati 1942: 17).

En efecto, el autor presenta, además de una "atribución étnica", referencias sobre "caracteres psicológicos", algunos "antecedentes" y luego un "catálogo bioiconográfico" que precede a la galería de setenta y nueve reproducciones fotográficas, casi el noventa por ciento de las cuales son retratos a la Bertillon (fs. 4 y 5).

El texto escrito, tanto como el conjunto de fotografías del artículo, podría dar lugar a un análisis extenso. Pero quiero hacer aquí sólo dos apuntes para el estudio de la "iconografía aborigen" científica argentina de fines del siglo XIX y principios del XX. Se trata apenas de relevar dos elementos presentes en el texto de Vignati, tan a la vista que pueden pasarnos desapercibidos. Relevarlos, detener nuestra mirada sobre ellos e interrogarlos. El primer apunte se relaciona con el carácter temprano de la fotografía de tipo racial en la antropología argentina. El segundo, con la dinámica social conflictiva que puede rastrearse congelada en estas tomas.

\section{Una visión temprana de la "raza"}

Vignati dedica la parte II de su Iconografía, de 1945, al cacique Casimiro Biguá y su hijo Sam Slick. El artículo presenta algunas imágenes de los dos. Comienza refiriendo a una fotografía aparecida en 1875 en Archives de la Société Américaine de France (Bermondy 1875). Sin tener la foto las características de las que conforman la parte I de "Iconografía...", muestra igualmente la imagen de Casimiro y su hijo en tanto "Types Tehuelches (Patagonie)" (fs. 6 y 7). La foto de los dos hombres de frente, de cuerpo entero, delante de un fondo claro y liso fue tomada en 1864, según los cálculos de Vignati, y es de autor anónimo -aunque atribuida a Benito Panunzi-. Otra imagen, que me resulta aun más sugerente, es el doble retrato del joven Sam "según una litografía inédita 


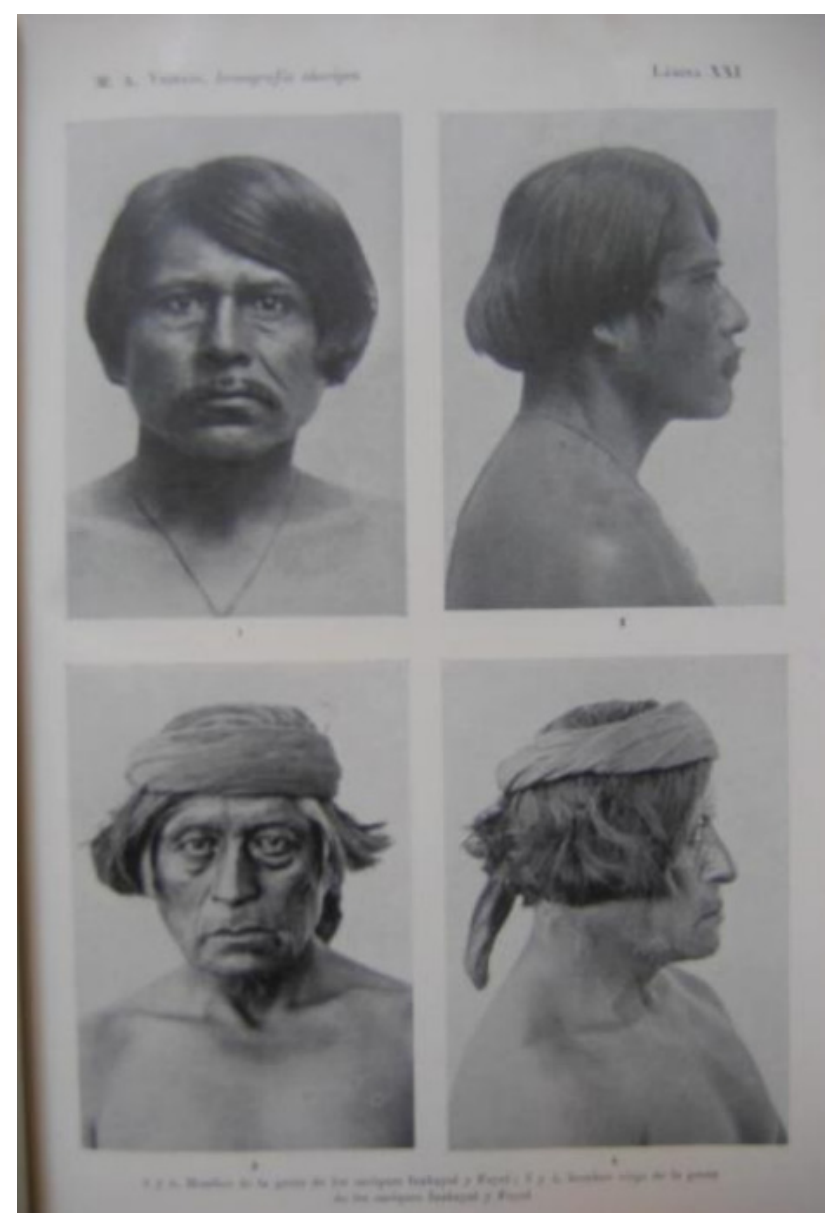

Figura 4. Vignati, Iconografía Aborigen, Revista del Museo de La Plata.

Figure 4. Vignati's Iconografía Aborigen, Revista del Museo de La Plata.

de Moreno" (f. 8). Francisco P. Moreno, fundamental para el trabajo de Vignati en tanto "promotor de la serie fotográfica" de la parte I, y a quien éste reconoce que la misma podría "haber[le] sido dedicada" (Vignati 1946: 279), es también a quien debemos este doble retrato que, "transportado a litografía, debía ilustrar el segundo tomo del Viaje a La Patagonia austral" (Vignati 1945: 235), proyecto editorial que Moreno nunca pudo concretar. En este retrato, el hijo del cacique es tomado de frente y de perfil, el quillango de cuero de guanaco caído por uno de los lados hasta la cintura, dejando ver su torso desnudo.

A simple vista cabría preguntarse si se trata de un retrato bertillonesco, pero muy difícilmente podría responderse de manera positiva a la pregunta y definir de esta manera la imagen. Cumple los requisitos formales, es cierto, pero el año de realización que señala Vignati, que es 1874, coloca un signo de interrogación. Los trabajos de Bertillon son posteriores, de inicios de la década de 1880, y, como reseña Poole, su primera publicación profesional es de 1882, cuando aún no había acabado de desarrollar su método, qué sería presentado en 1885 en el Congreso de Antropología Criminal de Roma (Penhos 2009).

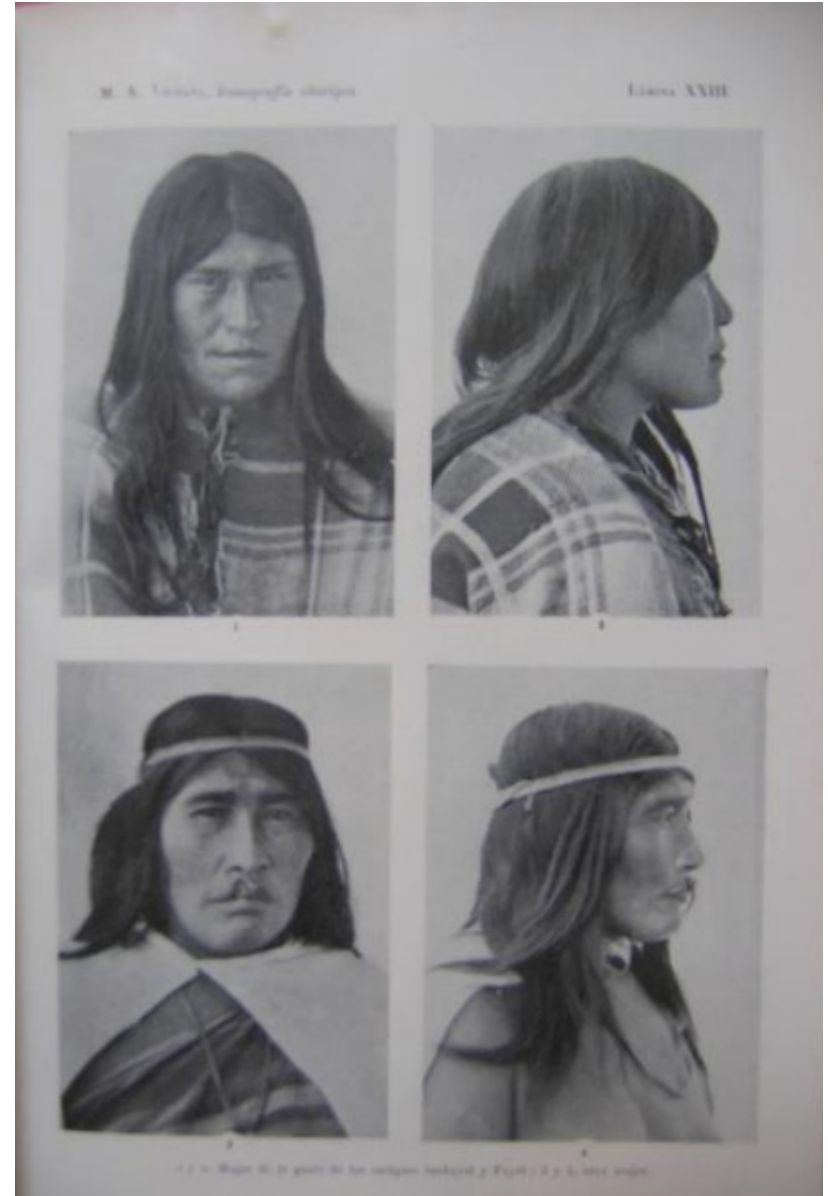

Figura 5. Vignati, Iconografía Aborigen, Revista del Museo de La Plata

Figure 5. Vignati's Iconografía Aborigen, Revista del Museo de La Plata.

Por su parte, Francisco P. Moreno, fundador y director del Museo de La Plata, viajó a Paris, donde completó su formación antropológica con el aludido Paul Broca, en 1879, cuando ya había realizado varios de sus viajes de exploración al sur argentino, en uno de los cuales se había tomado la fotografía en cuestión ${ }^{5}$. Por cierto, sus

5 Moreno llevó adelante sus primeras exploraciones en 1871, en 1873 llegó a Carmen de Patagones y en 1874, invitado por el gobierno, formó parte de una expedición al Río Santa Cruz, en la Patagonia austral. Desde antes había comenzado a formar sus colecciones, en parte aprovechando los contactos propios y de su padre, por ejemplo con comerciantes del sur que le hacían llegar cráneos y utensilios indígenas, extraídos de cementerios (Farro 2009: 44 y ss.). Aunque no es necesario insistir en la importancia intelectual y, sobre todo, institucional y política de Moreno, cabe tener presente que ha sido considerado uno de los iniciadores de la antropología en Argentina, en su carácter de "científico explorador". Acerca de las relaciones e intercambios científicos e institucionales a nivel internacional, es interesante la presentación que de él hace la portada de su Viaje a la Patagonia austral...: "Director del Museo Antropológico y Arqueológico de Buenos Aires y Gefe (sic) de la Comisión Exploradora de los Territorios Australes. Doctor ad-honorem de la Universidad Nacional Miembro de la Academia Nacional de Ciencias de la República Argentina - Miembro Académico de la Facultad de Ciencias Físico-naturales de Buenos Aires - Miembro honorario del Círculo Médico Argentino - Miembro honorario de la Sociedad Italiana de Antropología y Etnología - Miembro corresponsal de la Sociedad de Antropología de París - de la Sociedad de Antropología, Etnología, etc., de Berlin - de 


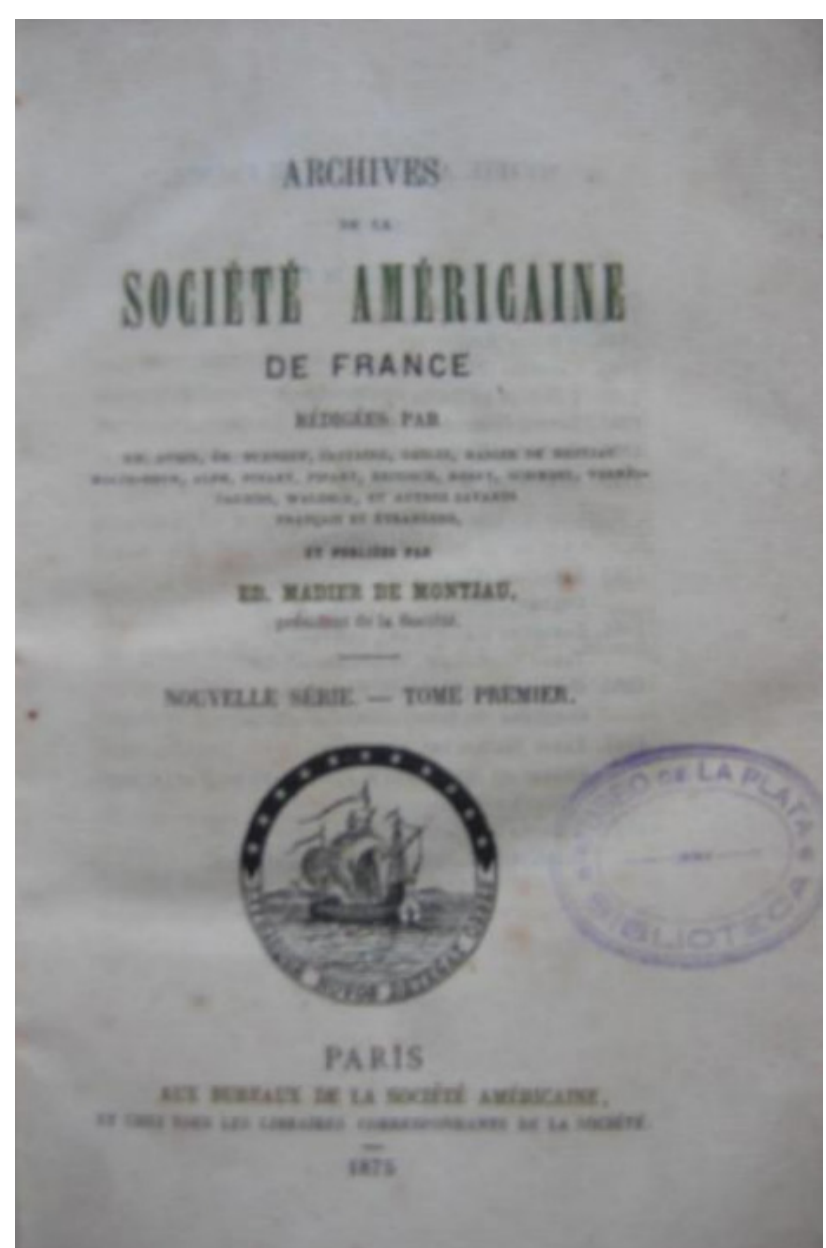

Figura 6. Archives de la Société Américaine de France.

Figure 6. Archives de la Société Américaine de France.

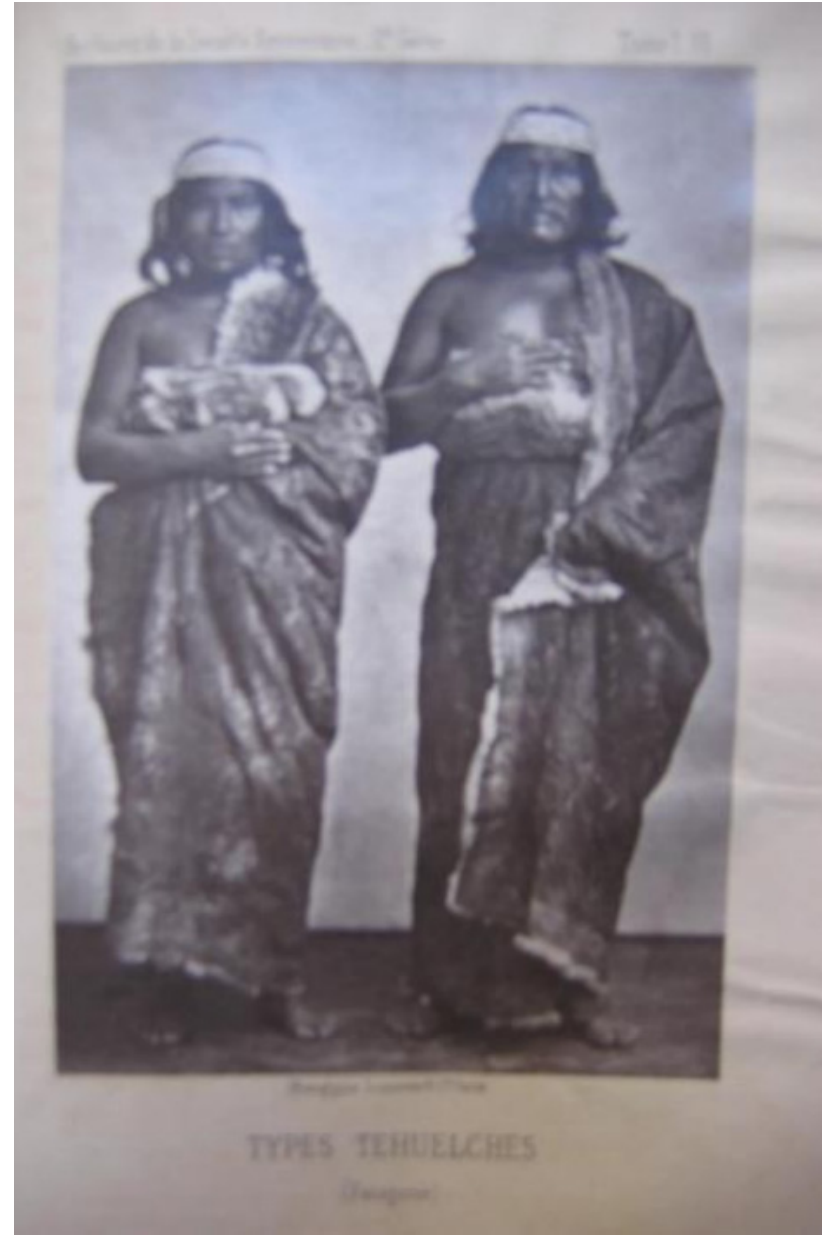

Figura 7. Bermondy, "Types Tehuelches" Archives de la Société....

Figure 7. Bermondy's Tehuelchian types Archives de la Société....

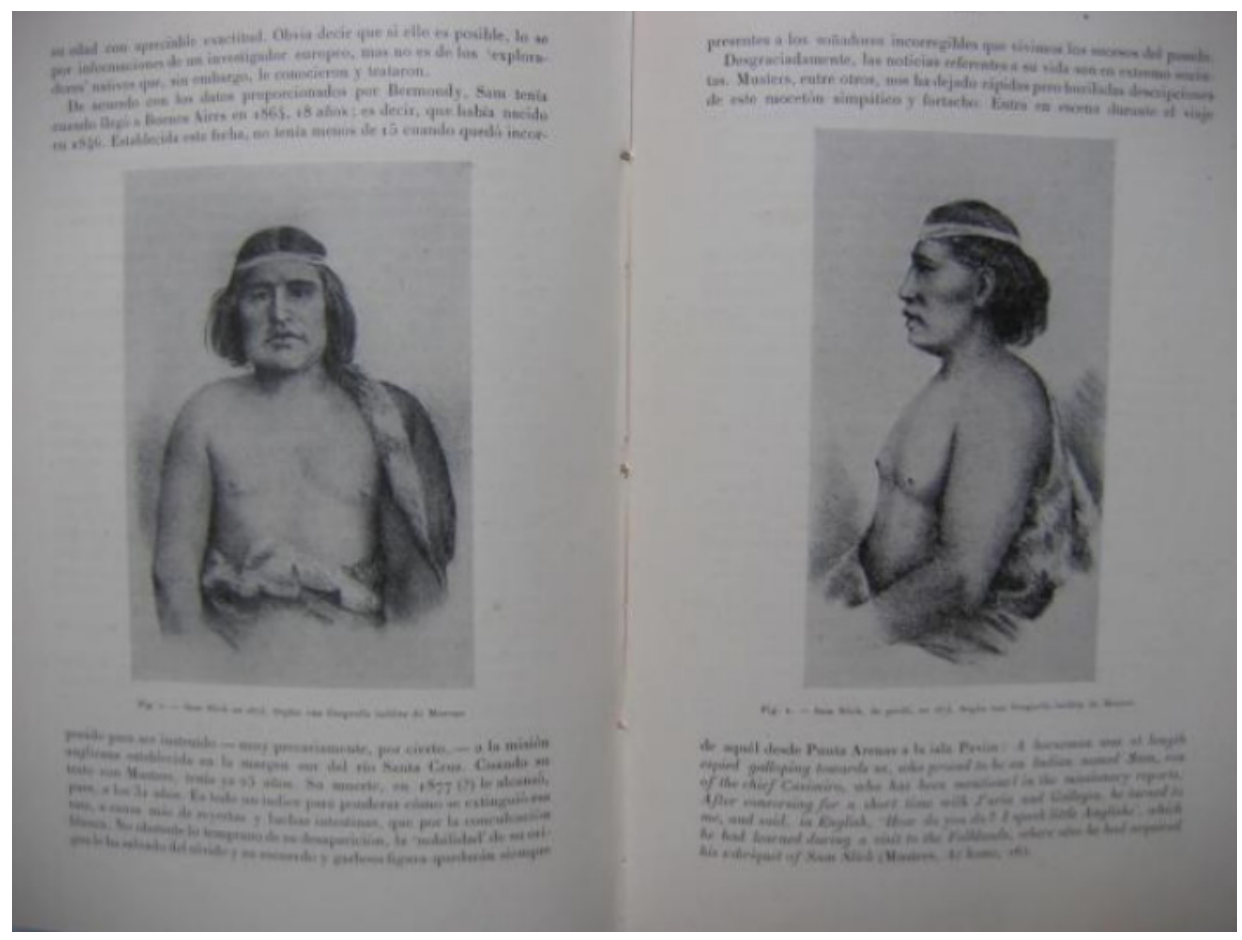

Figura 8. Sam Slick, "litografía inédita de Moreno", Vignati, I. A., Revista del Museo de La Plata.

Figure 8. Sam Slick, Moreno's unpublished lithograph, Vignati, I. A., Revista del Museo de La Plata. 
contactos internacionales eran anteriores. Entre 1874 y 1880 publicó trabajos en la Revue d'Anthropologie y el Bulletin de la Société d'Anthropologie, ambos de París, y mantuvo intercambios con numerosos antropólogos europeos, como Pierre Topinard y Rudolf Virchow, que apoyaron sus emprendimientos, entre otras cosas porque los hallazgos conseguidos por él, como los cráneos y datos que remitía a Europa, podían avalar algunas de sus teorías (Quijada 1998).

Con Broca, en particular, se vinculaba desde comienzos de la década de 1870, y sin dudas podemos rastrear en este vínculo un elemento clave para entender la realización de estas fotografías. En sus exploraciones Moreno siguió las "instrucciones generales" redactadas por Broca y publicadas en 1865 para ser utilizadas por viajeros y corresponsales de la Société d'Anthropologie (Farro 2009: 79). En ellas puede hallarse una temprana indicación acerca de cómo tomar fotografías. La instrucción es precisa al señalar que las fotos de la cabeza ("desnuda") se tomarán "exactamente de frente o exactamente de perfil" (Broca 1865: 6). Es, al mismo tiempo, sumamente escueta, lo cual no sorprende dado que la técnica fotográfica recién comenzaba a difundirse. Broca dedica apenas media cuartilla al apartado, de las quince páginas que forman el capítulo sobre "colecciones antropológicas", que se completa con una sección sobre "moldes en yeso" y una sobre "piezas anatómicas".

¿Cuándo, cómo y dónde es el proceso de consolidación de esta tecnología visual que es la fotografía de tipos raciales? Resulta altamente improbable que se hayan originado autónomamente en las grandes ciudades de Europa para difundirse luego a las ex colonias. Siguiendo a Poole, parece pertinente buscar más allá de la mirada policial de inspección y control en las ciudades europeas crecidas e inseguras de fines del siglo XIX, y ese "buscar más allá" podría implicar, en otro sentido, "buscar más acá". Así como las cartes de visite andinas y otras que llegaban a Europa desde las colonias serían fundamentales para repensar la historia de la fotografía y de los tipos raciales, tal vez haya que reparar también en el papel que en estos intercambios jugaron las imágenes científicas que llegaban desde el extremo sur de América que, como se sabe, era una región que despertaba particular interés a la ciencia europea desde la visita de Darwin cuatro décadas antes.

La configuración de este modo de ver (Berger 1972), que es a la vez un modo de conocer, es un proceso complejo que tendrá un momento fuerte en el sistema de Bertillon. Ha llevado por lo menos dos décadas, entre la escueta indicación escrita de Broca y otras semejantes (Dias 1994) y su concreción en imágenes que operarán diferentes personas en distintos lugares. Se sabe, por

la Sociedad Real de Ciencias de Liége - y de la Sociedad Mejicana de Historia Natural - Miembro de la Sociedad Geográfica Italiana, etc." (Moreno 1879: Portada). ejemplo, de ensayos de diversos "métodos fotométricos" en las colonias inglesas que, de una u otra forma, remitían a dos sistemas principales desarrollados en la década de 1870, el de Thomas Huxley, que recomendaba desnudar a los sujetos a ser fotografiados e indicaba ciertas poses antropométricas, una distancia fija de la cámara y, también, la doble foto de frente y de perfil, y el de John Lamprey, que estipulaba que el sujeto fuera fotografiado con un plano cuadriculado como fondo, es decir, un panel sin otra cosa que líneas verticales y horizontales cruzándose y formando pequeños cuadrados, estandarizados para todas las fotos, lo cual permitiría la comparación general y por partes de la morfología corporal (Spencer 1992; Pinney 1992). ¿Qué otras intervenciones se han dado en el proceso?, ¿qué intercambios, préstamos y retroalimentaciones han tenido lugar?

Pero además se han hallado antecedentes visuales más tempranos. En este sentido, precisamente trabajando con imágenes patagónicas, Marta Penhos encuentra ejemplos anteriores de representaciones de "indios" según el formato de doble retrato, de frente y de perfil. Es el caso de una serie de dibujos producidos durante el segundo viaje que realizara Robert Fitz-Roy, al mando del Beagle, a Tierra del Fuego, entre 1831 y 1836 . Fueron retratados "varios individuos, de diferentes grupos, dibujando el rostro y el cuerpo hasta el busto de frente, de perfil o tres cuartos perfil, sobre un fondo absolutamente neutro" (Penhos 2005: 42). Incluso la autora va aun más atrás en el tiempo y señala que las planchas de ilustraciones de cuatro y seis rostros que aparecían en los manuales para artistas utilizados desde el siglo XVII pueden haber servido como modelo para los dibujos de Fitz-Roy. ${ }^{6}$

En síntesis, no se trataría de descartar un presunto origen autónomo para postular otro alternativo, sino de intentar reconstruir la circulación epistemológica, teórica y política que en un momento cristalizó en esta "mirada científica" sobre los tipos humanos (raciales, criminales y ambas cosas juntas). Reponer las continuidades y discontinuidades en la historia de la conformación de este modo de ver ayudaría a comprender las conjunciones de un trabajo científico que en el siglo XIX separaba campo y gabinete, o bien recolección de datos e interpretación de los mismos (Dias 1994). Ayudaría también a apreciar en estos productos del trabajo científico la integración de aportes de diferentes intereses, tradiciones y estilos locales. En otros términos, entender la concordancia

\footnotetext{
6 Ciertamente las diferencias entre dibujos como los de Fitz-Roy y la fotografía de tipo son fundamentales. En efecto, Penhos reconstruye el pasaje desde la percepción y descripción romántica de un "personaje" dibujado o pintado hacia la posesión e investigación de un "objeto científico" fotografiado (Penhos 2005: 20 y ss.). En este encuadre, si aquellos dibujos buscaban ser "la demostración exterior de los estados interiores", la posterior fotografía de tipo apuntaría a ser "la evidencia física de los datos de una realidad que responde a unas leyes de las que el hombre no escapa" (Penhos 2005: 43). Acerca de las migraciones de estos dibujos entre diferentes libros del siglo XIX, ver Penhos (2009).
} 
y los aportes mutuos entre estas observaciones, experimentaciones y teorías, que se daban en lugares de Europa, como París, al tiempo que en los Andes estudiados por Poole, en el Cono Sur y en otras regiones.

\section{Tensiones sociales fijadas en la foto}

En esta misma parte II de su "Iconografía..." Vignati cede la palabra a Moreno en la narración de los contactos que éste mantuviera con Sam Slick, el hijo del cacique Biguá. Moreno refiere regalos, ponches con que obsequiaba al joven tehuelche y viajes en bote compartidos.

"En esa circunstancia -señala Vignati- fué (sic) cuando consintió que le fotografiara, más no que le hiciera antropometría. «No sé por qué rara preocupación hacía esto -indica Moreno-, pues más tarde, al volver a encontrarle en Patagones, aun cuando continuamos siendo amigos, no me permitió acercarme a él, mientras permanecía borracho, y un año después, cuando llegué a ese punto para emprender viaje a Nahuel-Huapi, le propuse me acompañara y rehusó diciendo que yo quería su cabeza. Su destino era ese. Días después de mi partida, dirijióse (sic) al Chubut y allí fué (sic) muerto alevosamente por otros dos indios, en una noche de orgía»".

Tras un punto y aparte, Vignati completa diciendo que "[v]uelto Moreno a Patagonia, supo de la muerte de Sam, procediendo a desenterrar su cadáver cuyo esqueleto se conserva en las colecciones antropológicas del Museo de La Plata" (Vignati 1945).

Por su parte, la "Iconografía aborigen I", como señalé, se conformó mayoritariamente con una serie de imágenes que Vignati infiere fueron encargadas por Moreno. A esas el autor agrega cuatro obtenidas por otro investigador del Museo, Herman ten Kate ${ }^{7}$, a quien cita en una larga nota al pie. Me interesa recuperar gran parte de esa cita:

“Los primeros - algunos araucanos- pertenecían a aquellos que, más o menos civilizados, viven -dice Ten Kate al año 1896- desde hace años dispersos entre los blancos. Se encuentran en el ejército y en la marina, en la policía y los bomberos; el resto hace un poco de todo, lo que significa no gran cosa. Aunque una docena de ellos habían sido convocados por nuestro director, el Sr. Moreno, a venir al Museo para que yo los midiera, estos araucanos se prestaban a ello de muy mala gana.

\footnotetext{
7 El antropólogo Herman F. C. ten Kate Jr. nació en Amsterdam y estudió en instituciones de varias ciudades de Holanda y otros países, como Alemania y los Estados Unidos. Anteriormente, en 1879, había estado en París. En los cursos que tomó allí conoció a Moreno, de quien publicó entonces una reseña de Viaje a la Patagonia Austral y de quien recibiría en 1892 la invitación a sumarse a trabajar en el Museo de La Plata, donde estuvo por unos años realizando tareas de campo y de gabinete (Farro 2009).
}

Pocas veces en mi vida de viajero-antropólogo he tenido que tener tanta paciencia como con estos indios. Como había dos agentes de policía entre ellos, habían oído hablar del servicio antropométrico de Bertillon, que se aplica también en La Plata. Pues bien, se imaginaban que mis investigaciones tenían algo que ver con la policía $y$, no queriendo ser tratados como vulgares malhechores, rechazaban someterse a ello [...] Sin embargo, todos se dejaron fotografiar" (ten Kate, citado en Vignati, 1942: 16-17, n. 1, traducción propia, agregados entre guiones de Vignati) $^{8}$.

Las dos citas comparten un aspecto fundamental que nos ayuda a pensar las relaciones sociales que están detrás de estas fotos de tipo, y que son relaciones de poder, resistencias, tensiones, conocimientos adquiridos, códigos en ocasiones compartidos, en ocasiones no, en ocasiones compartidos a medias. En la primera escena, el joven Sam Slick no consiente que se practiquen sobre él las mediciones antropométricas, y el también joven Moreno no entiende la causa de su negativa. Moreno asocia esto al hecho de que por esos días Sam rehusara acompañarlo a una excursión creyendo que él "quería su cabeza". (Por cierto, la colección de cráneos de Moreno se engrosaba en sus travesías por la Patagonia, y es muy probable que Sam Slick sospechara algo acerca de cuál sería "su destino", no tanto a manos de los "otros dos indios", sino en manos de Moreno.) La fotografía de frente y perfil está claramente asociada a la antropometría (y al futuro del esqueleto) y carga con las relaciones condensadas en esta escena, con sus miedos e incomprensiones, con las mediciones de fuerza. Al mismo tiempo, evidentemente la fotografía merece algún valor o consideración diferente a la antropometría por parte de Sam, pues sí accede a ser fotografiado. Seguramente había visto las fotos de otros caciques o "caciquillos", o la suya propia y de su padre tomada unos años antes (f. 7), en ocasión de la visita que ellos realizaran a Buenos Aires junto a otros indígenas del sur. Sam Slick no permitió las mediciones antropométricas, no pudo luego no permitir la apropiación de su cuerpo muerto y sí permitió, antes, la fotografía. Relaciones, acciones y fuerzas diversas.

Algo semejante sucede en la segunda escena con la

8 Vignati conserva el francés original en la cita de ten Kate y realiza sus agregados en español: "Les premiers -algunos araucanos- appartenaient à ceux qui, plus ou moins civilisés, vivent -dice Ten Kate al año 1896- depuis des annés dispersés au milieu des blancs. On les trouve dans les armées de terre et de mer, dans la police et les pompiers; le reste fait un peu de tout, ce qui veut dire pas grand chose. Quoiqu'une douzaine d'entre eux eussent été convoqués par notre directeur, M. Moreno, à venir au Musée pour étre mesurés par moi, ces araucans s'y prêtaient de très mauvaise grâce. Rarement dans ma vie de voyageur-anthropologiste j'ai du avoir tant de patience qu'avec ces Indiens. Comme il y avait deux agents de police parmi eux, ils avaient entendu parler du service anthropométrique de Bertillon, tel qu'on I'applique aussi à La Plata. Or, ils se figuraient que mes recherches avaient quelque choise à faire avec la police et ne voulant pas être traités comme des vulgaires malfaiteurs, ils refusaient de s'y soumettre [...] Tous se laissaient photographier cependant". 
docena de "araucanos" "convocados" al Museo para ser medidos ${ }^{9}$. Las breves consideraciones de ten Kate encierran una gran riqueza. Sabe, para empezar, que a muchos de estos indios "más o menos civilizados" se los puede encontrar ya en 1896 reclutados para trabajar en las fuerzas armadas o la policía. Al parecer, es justamente porque dos de entre los "convocados" son agentes de policía que se desatan las fricciones. Los "araucanos" se imaginan que los estudios bertillonescos tienen algo que ver con la policía (sorpresivamente ten Kate se sorprende por ello) y rechazan someterse a los mismos. "Sin embargo, todos se dejan fotografiar". Nuevamente una dinámica ardua y desigual de relaciones sociales se deja ver entre el antropólogo viajero de colmada paciencia y los indios, quienes responden a veces de una manera, a veces de otra. Imposiciones, y también proposiciones y denegaciones.

Existen algunos trabajos en los que se puede leer acerca de indicios de resistencia de los/as fotografiados/as en las fotografías antropológicas de esta época (Masotta 2003), pequeños gestos, miradas huidizas o párpados que caen procurando guardar la propia imagen. Es que estas fotografías, como casi todas, no pueden evitar mostrar relaciones sociales, y las relaciones implican al menos dos partes. En los casos que presento, además, los textos testimonian negociaciones muy claras antes de que se apretara el obturador. Los indios tenían conocimiento de la fotografía y de la antropometría y, por alguna razón, o por varias combinadas, aceptaron la primera y rechazaron la segunda. Seguramente los usos policiales de esta última tuvieron su peso, acaso también el mayor efecto de captura del cuerpo que las mediciones comportarían en relación con la fotografía, y probablemente, por último, la creciente difusión social que la técnica fotográfica tenía por entonces, que la habría vuelto algo más familiar.

\section{Al mismo tiempo, las fotos de Sam Slick de Moreno como}

\footnotetext{
9 Las comillas en "araucanos" buscan, por un lado, indicar que la categoría está actualmente en desuso, tanto entre quienes podrían sentirse parte de ese pueblo, como entre antropólogos/as, y buscan, por otro lado, advertir sobre las implicaciones políticosimbólicas de la categoría asociada a la noción de "araucanización". Como han mostrado Lazzari y Lenton (2000), la consolidación de la hipótesis de este fenómeno "migratorio y aculturativo" que habrían emprendido grupos araucanos desde Araucanía (en el actual Chile) hacia Pampa y Norpatagonia (en la actual Argentina) muestra la particular "relación entre el discurso etnológico y el discurso nacional" alrededor de la década de 1930. "Esta narrativa hegemónica propicia el reconocimiento en el interior de la nación argentina, de entidades marcadas no solamente como «grupos étnicos» indígenas -araucanos de ayer, mapuche de hoy-, sino también diacritizados como «invasores», «extranjeros» 0 , en el mejor de los casos, «recién \|legados»" (Lazzari y Lenton 2000: s/p). En cuanto a las comillas en "convocados", buscan recordar que, en rigor, se trataba de indígenas tomados prisioneros por el gobierno nacional y enviados a Buenos Aires, más precisamente a Tigre, donde permanecerían por un año y medio hasta que Moreno solicitara su traslado al Museo de La Plata. Allí, además de ser expuestos a los visitantes, sirvieron como "obreros cautivos", realizando tareas diversas (Podgorny y Lopes 2008: 226227).
}

las de los "araucanos" de ten Kate han resultado de negociaciones múltiples, y no sólo de la más ostensible y desnivelada entre los antropólogos y los "indios". Las dos escenas ofrecen pistas para seguir el rastro de otros costados de estos procesos de negociación múltiples. ¿Quién decidió que se accediera o no a las fotos o a las mediciones?

Vale recordar que, desde por lo menos el segundo cuarto del siglo XIX, hubo diversos pactos y acuerdos entre las instituciones porteñas o argentinas y los "indios amigos". Era relativamente común que, producto de estas relaciones, algunos caciques fueran convertidos en oficiales del ejército o recibieran del Estado otros cargos y competencias. El propio cacique Casimiro, el padre de Sam Slick, mantuvo relaciones de este tipo con el presidente argentino Bartolomé Mitre (de allí el viaje a Buenos Aires en que se les tomaría la foto de la figura 7), al tiempo que se vinculaba con el gobierno chileno en Santiago. Con el correr de los años algunos indígenas serían incorporados a otras instituciones, como las que menciona ten Kate. Estas relaciones -siempre tensas- entre el Estado y los líderes indígenas facilitaron las exploraciones de Moreno a la Patagonia, con sus recolecciones y fotografías. Además de comerciantes asentados en distintas localidades del sur, coroneles del ejército oficiaron como intermediarios locales entre aquel y varios caciques y capitanejos indígenas de la región, y fue el propio presidente Sarmiento quien en 1874 "lo había puesto en contacto con el cacique Inacayal llevándolo al domicilio de Moreno" (Farro 2009: 48)

Aparecen entonces aquí hombres (varones) ocupando determinadas posiciones: junto a los científicos y exploradores, representantes estatales, militares, comerciantes, caciques y otros dirigentes indígenas. En el contexto de producción de estas imágenes visuales, ¿cómo se ordenaban y reordenaban las fronteras entre los propios y los extraños, cómo las fronteras internas a "nosotros" heterogéneos? Valdría continuar las indagaciones acerca del modo en que intervenían la lógica política y lo que, en términos contemporáneos, llamaríamos la lógica de género en la estructuración de estas imágenes y de esta imaginación. ¿En quién pensaba Sam Slick a la hora de aceptar ser fotografiado?, ¿en Moreno?, ¿en "sus indios", en "sus indias"?, ¿en su padre?, ¿en otros caciques?, ¿en miembros de la sociedad blanca? ¿Qué elementos habrá considerado en su decisión?, ¿sólo se trataba de una cuestión de cesión o resistencia frente a Moreno, o eventualmente podía también incidir el prestigio, el honor u otros factores de cara a los suyos? ¿Con quién negociaba el hastiado ten Kate?, ¿con todos?, ¿con los dos indios policías?, ¿con otros?, ¿con los indios o con las indias? Claro que los que eran policías sabían de estas técnicas; con el tiempo, ellos o sus sucesores aprenderían a utilizar el método de Bertillon y a aplicarlo a otros. Otros harían otras cosas, desde luego. Lo interesante es el conocimiento de las 
técnicas por parte de "los indios" así como las diferencias entre ellos. Además de indios policías, como indica ten Kate, encontramos bomberos y miembros del ejército o la marina dispersos entre los blancos. Más tarde, cuando otras instituciones del Estado se agreguen, complejizarán todavía más estos límites entre quienes estaban aquí a un lado y otro de la cámara.

Relaciones desiguales, diferencias y negociaciones entre los que tomaban las fotos y sus "objetos", así como entre los propios indios e indias, instituciones estatales a un lado y a otro de esa barrera, colocando otras distinciones, otros clivajes y vías de incorporación. Dinámicas sociales intrincadas habitan la imagen quieta, contenida por los bordes de la foto, tensiones y acuerdos que pueden emerger del cuadro en apariencia inerte. Aun la tan regulada fotografía de tipo, con su realización codificada y controlada, puede mostrar, observada con detenimiento, las relaciones sociales de las que es producto.

Y el desafío se redobla: a la pregunta por la amplitud de la circulación de miradas, experimentaciones y teorías que, a un lado y al otro del Atlántico, habrían engendrado la visión de la "raza", debe añadirse entonces la pregunta acerca de estos enredos locales, que se desarrollaban y configuraban con cada ejecución, y que daban forma a las imágenes y a los textos que las acompañaban e interpretaban.

\section{Bibliografía}

Arendt, H. 1973. The Origins of Totalitarianism, New York, H. Brace.

Balibar, E. 2003. Election/Sélection. Adaptación al francés de la segunda parte de la presentación al Coloquio traces. Race, Deconstruction, and Critical Theory, Universidad de California, mimeo.

Banton, M. 1977. The idea of race, Tavistock, Londres.

Batut, A. 1887. La photographie appliquée a La Production du Type d'une familla, d'une tribu ou d'une race, Gauthier-Villars, Paris.

Berger, J. 1972. Ways of seeing, British Broadcasting Corporation and Penguin Books, London.

Bermondy, T. 1875. Les Patagons, les Fuegans et les Araucans. Archives de la Société Américaine de France, nueva serie, Tomo I: 355-366.

Broca, P. 1865. Instructions générales pour les recherches et observations anthropologiques (anatomie et physiologie), Victor Masson et fils, París.

Caggiano, SeSrgio. 2012. El sentido común visual.
Disputas en torno a género, "raza" y clase, Miño y Dávila editores, Buenos Aires.

Dias, N. 1994. Photographier et mesurer : les portraits anthropologiques. Romantisme 84: 37-49.

Edwards, E. 1992. Anthropology and Photography. 18601920, Yale University Press and The Royal Anthropological Institute, New Haven and London.

Farro, M. 2009. La formación del Museo de La Plata. Coleccionistas, comerciantes, estudiosos y naturalistas viajeros fines del siglo XIX, Prohistoria ediciones, Rosario.

Fígoli, L. 2004. Origen y desarrollo de la antropología en la Argentina: de la Organización Nacional hasta mediados del siglo XX. Anuario de Estudios en Antropología Social, IDES - Editorial Antropofagia, Buenos Aires: 71-80.

Garrido, M., T. Kelly, A. Martínez e I. Podgorny. 2007. Caras desdibujadas en la arena. Las colecciones fotográficas del Acervo Histórico de la Facultad de Ciencias Naturales y Museo de la Universidad Nacional de La Plata. Museo, vol. 3, núm. 21: 67-72.

Guillamin, C. 2002. L'idéologie raciste. Genèse et langage actuel, Gallimard, Paris.

Lazzari, A. y D. Lenton. 2000. Etnología y nación: facetas del concepto de araucanización. Avá - Revista de Antropología, núm. 1, UNM, Posadas. (Versión mimeo.)

Lehmann-Nitsche, R. 1907. Estudios antropológicos sobre los Chiriguanos, Chorotes, Matacos y Tobas (Chaco Occidental). Anales del Museo de La Plata, Tomo I, Segunda Serie, Buenos Aires: 7-190.

Malik, K. 1996. The Meaning of Race. Race, History and Culture in Western Society, Mac Millan, Londres.

Martínez, A. y L. Tamagno. 2006. La naturalización de la violencia: Un análisis de fotografías antropométricas de principios del siglo XX. Cuadernos Antropología Social, jul./dic., núm. 24: 93-112.

Masotta, C. 2003. Cuerpos dóciles y miradas encontradas. Miniaturización de los cuerpos e indicios de la resistencia en las postales de indios argentinas (1900-1940). Revista Chilena de Antropología Visual, núm 3, http://www. antropologiavisual.cl/artmassota.htm (Última consulta: 02/08/2012)

Penhos, M.N. 2005. Frente y perfil. Una indagación acerca de la fotografía en las prácticas antropológicas y criminológicas en Argentina a fines del siglo XIX y principios del XX. VVAA, Arte y antropología en la Argentina, cap. 1: 15-64, Fundación Espigas, Buenos Aires. 
Penhos, M.N. 2009. Imágenes viajeras: de la expedición del "Beagle" a L'Universe Pittoresque. Podgorny, I., M. Penhos y P. Navarro Floria, Viajes. Espacios y cuerpos en la Argentina del siglo XIX y comienzos del XX, cap. 2: 45-87, Teseo, Buenos Aires.

Pinney, C. 1992. The Parallel Histories of Anthropology and Photography. Edwards, Elizabeth (ed.), Anthropology and Photography. 1860-1920, Yale University Press and The Royal Anthropological Institute, New Haven and London.

Podgorny, I y M.M. Lopes. 2008. El desierto en una vitrina. Museos e historia natural en la Argentina, 18101890, Limusa, México.

Poole, D. 2000. Visión, raza y modernidad. Una economía visual del mundo andino de imágenes, Sur Casa de Estudios del Socialismo y Consejería en Proyectos, Lima.

Quijada, M. 1998. Ancestros, ciudadanos, piezas de museo. Francisco P. Moreno y la articulación del indígena en la construcción nacional argentina (siglo XIX). Estudios Interdisciplinarios de América Latina y el Caribe, Tel Aviv.

Sekula, A. 1992. The Body and the Archive. Bolton, Richard (ed.), The Contest of Meaning: Critical Histories of Photography, The MIT Press, Massachussets.

Smith, S. M. 1999. American Archives. Gender, Race, and Class in Visual Culture, Princeton University Press, New Jersey.

Smith, S. M. 2004. Photography on the Color Line. W.E.B. Du Bois, Race, and Visual Culture, Duke University Press,
Durham \& London.

Soprano, G. s/f. La antropología física entre la universidad y el Estado. Análisis de un grupo académico universitario y sus relaciones con las políticas públicas del Instituto Étnico Nacional (1946- 1955). Disponible en Saberes de Estado y Elites Estatales, http://saberesdeestado.ides.org. ar (Última consulta: 12/04/2013)

Spencer, F. 1992. Some Notes on the Attempt to Apply Photography to Anthropometry during the Second Half of the Nineteenth Century. Edwards, E. (ed.), Anthropology and Photography. 1860-1920, Yale University Press and The Royal Anthropological Institute, New Haven and London.

Stocking Jr., G. W. 1968. Race, Culture and Evolution. Essays in the History of Anthropology, The Free Press, New York.

Vignati, A. M. 1942. Iconografía aborigen I. Los caciques Sayeweke, Inakayal y Joyel y sus allegados. Revista del Museo de La Plata (nueva serie), sección Antropología, núm. 10, Tomo II: 13-48.

Vignati, A. M. 1945. Iconografía aborigen II. Casimiro y su hijo Sam Slick. Revista del Museo de La Plata (nueva serie), sección Antropología, núm. 13, Tomo II: 225-236.

Vignati, A. M. 1946. Iconografía aborigen III. La tribu del cacique Ólkelkkēnk. Revista del Museo de La Plata (nueva serie), sección Antropología, núm. 15, Tomo II: 278-289.

Williams, R. 2000. Marxismo y Literatura, Península/ Biblos, Barcelona. 